\title{
A Mathematical Model of Intermittent Gas Lift in Elevation-Production Operation with Line-Pack and Line-Drafting Phenomena in a Gas Line
}

Silvya Dewi Rahmawati ${ }^{*}$, Tasmi Tasmi ${ }^{2}$, Pudjo Sukarno ${ }^{1}$, Agus Yodi Gunawan ${ }^{3}$, Edy Soewono ${ }^{3}$, Septoratno Siregar ${ }^{1}$, Edward L Tobing ${ }^{4}$

${ }^{1}$ Drilling, Production Engineering, Oil \& Gas Management Group, Department of Petroleum Engineering, Faculty of Mining and Petroleum Engineering, Institut Teknologi Bandung, Jl. Ganesha 10, Bandung, West Java, Indonesia 40132

${ }^{2}$ Department of Computer Science, Faculty of Science and Computer Sciences, Universitas Pertamina, Jalan Teuku Nyak Arief, Simprug, Kebayoran Lama, Jakarta, Indonesia - 12220

${ }^{3}$ Department of Mathematics, Faculty of Mathematics and Natural Sciences, Institut Teknologi Bandung, Jl. Ganesha 10, Bandung, West Java, Indonesia - 40132

${ }^{4}$ Pusat Penelitian dan Pengembangan Teknologi Minyak dan Gas Bumi, LEMIGAS, Jl. Ciledug Raya Kav. 109, Cipulir, Kebayoran Lama, Jakarta Selatan, Indonesia - 12230

*Corresponding Author: $\underline{\text { sdr@tm.itb.ac.id }}$

\begin{tabular}{|c|c|}
\hline Article History: & Abstract \\
\hline $\begin{array}{l}\text { Received: July } 12,2020 \\
\text { Receive in Revised Form: September 22, } \\
2020 \\
\text { Accepted: September } 28,2020\end{array}$ & \multirow{3}{*}{$\begin{array}{l}\text { This paper discusses a transient model of the intermittent gas lift } \\
\text { technique in an oil well. The model is developed in the gas line, in } \\
\text { the tubing-casing annulus, and the tubing. The line-pack and line- } \\
\text { drafting phenomena in the gas line are considered in the model. A } \\
\text { numerical approach will be used to solve the mathematical model } \\
\text { that represents fluid flow during intermittent gas lift injection. The } \\
\text { dynamics of important variables in the intermittent gas lift are } \\
\text { investigated and analyzed to determine the best production strategy } \\
\text { for intermittent gas lift. The variables are film thickness and } \\
\text { velocity, slug height and velocity, and gas height and velocity. The } \\
\text { relationships between surface injection control parameters (gas } \\
\text { injection pressure and gas injection rate) and the velocity and height } \\
\text { of film, gas, and liquid are shown in one cycle of the gas lift } \\
\text { intermittent process. The higher the gas injection pressure, the faster } \\
\text { the gas injection velocity, and the thinner the film thickness in the } \\
\text { tubing. In order to obtain clean tubing from film thickness, the gas } \\
\text { injection pressure needs to be optimized, which will lead to } \\
\text { maintaining compressor discharge pressure availability. Detailed } \\
\text { observation of the dynamic performance inside the tubing } \\
\text { production well will give the optimum oil production rate for oil } \\
\text { wells under a gas lift intermittent production strategy for field } \\
\text { application. }\end{array}$} \\
\hline Keywords: & \\
\hline $\begin{array}{l}\text { Intermittent Gas-Lift, Transient Model, } \\
\text { Line-Pack, Line-Drafting, Dynamics of } \\
\text { Variables, Design Intermittent Gas Lift. }\end{array}$ & \\
\hline
\end{tabular}

\section{INTRODUCTION}

Artificial lift technology for oil production has been well developed to overcome declining production. The working principle of artificial lift implementation is located around wellbore and tubing areas. Originally, artificial lift technology included gas lift, sucker rod pump (SRP), electrical submersible pump (ESP), progressive cavity pump (PCP), and plunger lift. Several current developments include modifications to the gas lift and pump design. The names and working principles might be different, but the basic concepts are mostly similar to the original artificial lift technology. Many oil fields around the world are operating at a mature stage, where the peak production was achieved many years ago. What is left of the oil is produced with low or very low reservoir pressure. The wells that produce with very low reservoir pressure will create intermittent production, where the oil requires some time to fill the wellbore and flow to the surface. 
The terminology used for intermittent production is also widely known for gas lift. Two gas lift designs have been implemented, that is, continuous injection and intermittent injection. Intermittent gas lift is defined as a periodic injection into the well. Two terminologies are characteristic of intermittent gas lift: a shut-in period and a production period. A shut-in period is a period when the gas flows in the gas line, but the choke injection is closed. The fluid from the reservoir is slowly moving to the tubing. In this period, the phenomenon of gas flowing in the gas line is similar to the line-pack phenomenon and the gas stored temporarily in the gas line. When the oil in the tubing is ready to be produced (the height of the oil column is above the gas injection valve), the injection choke will be opened, and the gas will flow into the tubingcasing annulus. Once the gas reaches the tubing, it will form a gas column, which is then used as a piston to propel oil to the surface. After the oil reaches the surface, the surface choke is closed again until the next cycle. An intermittent gas lift system is shown in Figure 1. The system is similar to the continuous gas lift injection that consists of a compressor, gas line, choke, mandrel, gas lift valve, tubing, production line, and separator. The shut-in and production periods are controlled through an injection choke at the surface.

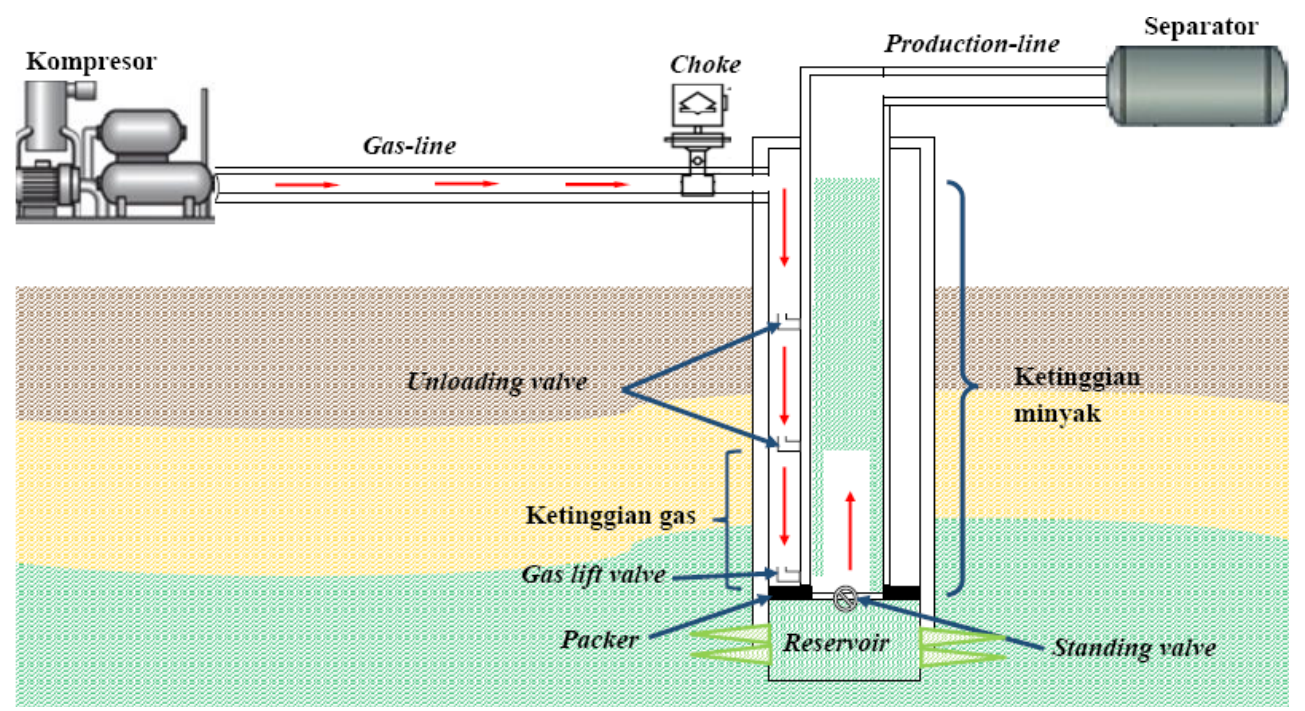

Figure 1. Cycle of intermittent gas lift (Tasmi et al., 2017)

Many studies have been conducted to determine the optimum parameters for intermittent gas lift production. The research has been done through laboratory experiments and mathematical models. Brill (1967) did research on intermittent gas lift through laboratory experiments with a well $457.2 \mathrm{~m}$ deep. The results show the variation in well performance with the length of initial liquid slug, volume of gas injection, and type of liquid from the reservoir. Brown (1980) conducted research on the intermittent gas lift on a well with depth $2438.4 \mathrm{~m}$, choke diameter of $\mathrm{m}$, and a gas lift valve with a depth of $1812.95 \mathrm{~m}$. Neely et al. (1974) also studied the intermittent gas lift through experiments using a well with a depth of $1524 \mathrm{~m}$. Musnal \& Fitrianti (2017) discussed optimization for continuous gas lift injection on four wells in field Labo. The gas injection rate became the optimization variable, while the maximum production rate was the objective function. Fitrianti et al. (2018) investigated important parameters on optimization for continuous gas lift. The parameters that considered were productivity index, gas-liquid ratio, depth of the well and reservoir's driving mechanism.

Liao (1991) developed a mechanistic model of intermittent gas lift. Liao's model represents the rise of liquid in the tubing, production of a liquid slug, production of liquid entrainment, and the regeneration of a liquid slug. Santos et al. (2001) extended Liao's model by adding a chamber, plunger, and pig. Filho \& Bordalo (2003) conducted research that covered the entire cycle of intermittent gas lift production. Bordalo \& Carvalho Filho (2007) studied an inverted intermittent gas lift, where the gas is injected through the tubing, and the liquid is produced from a casing. Pestana (2011) studied intermittent gas lift considering momentum conservation of the liquid film changes. Pestana et al. (2013) developed an intermittent gas lift model using a throttling valve. Aliev \& Jamalbayov (2015) showed a model of a gas-liquid mixture in the well and reservoir.

Shao et al. (2016) used a plastic bag model to represent a gas lift operation in a well. Pestana et al. (2013) and Tasmi et al. (2017) added a model of the gas flow in the gas injection flowline. The differences lie in the flow correlation used to model the pressure drop. Pestana et al. (2013) used Weymouth correlation and mass conservation to predict pressure in the choke. Tasmi et al. (2017) used line-pack and line-drafting to model the gas injection flow. In this research, the model combined line-pack and line-drafting models 
with the elevation production model developed by Liao (1991). The models were used to observe the effect of gas injection from the compressor to the tubing. The behaviour of parameters that influence the process was investigated. Therefore, the optimum parameters can be determined to obtain the maximum oil rate from a reservoir.

This research will be focused on the development model between surface injection pipeline and oil well with intermittent gas lift. The phenomena itself is unique, due to the surface injection pipeline will experience line-packing and line-drafting modes, which is currently implemented only for gas production pipeline transportation. The connection between surface and tubing represents the capability of a certain amount of injected gas and injected pressure to lift the liquid slug. The phenomena that cannot be neglected and different between continuous gas lift injection and intermittent gas lift injection was a liquid film around the tubing-wall. This condition may not appear for continuous gas lift injection due to the nonstop injected gas.

\section{MODEL OF INTERMITTENT GAS LIFT}

The intermittent gas lift method is used to produce oil from the reservoir to the surface. The intermittent gas lift technique is similar to continuous gas lift, but this method has unsteady-state flow. Before the gas is injected into the tubing, the choke is closed; however, the gas keeps flowing from the compressor to the gas line. Gas is injected when the oil is ready to be produced, or the oil reaches a certain height in the tubing. During the gas injection, the surface injection choke is opened, so that gas can flow to the annulus and tubing.

In the tubing, gas propels oil to the surface. When the oil reaches the tubing, the gas injection is stopped, that is, the gas injection choke at the surface is closed again. When the choke is closed, the gas used for the injection will still be flowing from the compressor to the gas line. Furthermore, the gas is stored temporarily in the gas line until the choke is opened again. In this study, the model of intermittent gas lift is divided into three domains of the flow: first, the flow of gas from the compressor to the gas line; second, the flow of the gas from the gas line (an injection choke) to the tubing-casing annulus; and third, the flow of gas and oil inside the tubing.

\section{Gas Line Model of Intermittent Gas Lift}

A gas injection flowline at the surface connects the compressor and the choke that closes the wellhead. Gas will flow continuously from the compressor to the gas line. Two conditions control the choke; opened and closed. A choke is opened when the oil is ready to be produced and closed when the oil reaches the surface. These controls will be used as a boundary condition of the flow model in the gas line. The model was developed based on the mass and momentum equations. The model of the gas flow in the pipeline is developed by Adewumi \& Zhou (1995) and Zhou \& Adewumi (1996). This model also used by Tasmi et al. (2017). In this study, the model adapted from the previous model. The gas-line model assumes there is no elevation in the horizontal gas injection line; there is a single-phase gas flow, isothermal condition, and the friction of the gas-line is in the steady-state condition. The initial and boundary conditions are adjusted to the field conditions. The gas line is in one of two conditions: line-pack when the choke is closed, and line-drafting when the choke is opened. Model of gas flow for a line-pack condition also studied by Sulistyarso et al. (2004). The models are adapted from Adewumi \& Zhou (1995) i.e.

$$
\frac{\partial \vec{Y}_{I}}{\partial t}+\frac{\partial \vec{G}_{I}\left(\vec{Y}_{I}\right)}{\partial x}=\vec{F}_{I}\left(\vec{Y}_{I}\right)
$$

Where

$$
\begin{gathered}
\vec{Y}_{I}=\left(\begin{array}{l}
\rho \\
\eta
\end{array}\right) \\
\vec{G}_{I}=\left(\begin{array}{c}
\eta \\
\frac{\eta^{2}}{\rho}+c^{2} \rho
\end{array}\right) \\
\vec{F}_{I}=\left(\begin{array}{c}
0 \\
-\frac{f \eta|\eta|}{2 D \rho}-g \eta \sin \alpha
\end{array}\right)
\end{gathered}
$$

The models of gas flow for horizontal model are developed by Adewumi \& Zhou (1995) and Zhou \& Adewumi (1996) i.e. for horizontal flow, $\vec{F}_{I}$ to be 


$$
\vec{F}_{I}=\left(\begin{array}{c}
0 \\
-\frac{f \eta|\eta|}{2 D \rho}
\end{array}\right)
$$

Initial conditions are $\rho(0,0)=\rho_{0}, \quad \eta(x, 0)=\eta_{0}$, and $\rho(x, 0)$ with $x \neq 0$ is solution of equation that obtained by Adewumi \& Zhou (1995) analytically. This equation i.e.

$$
\frac{D}{f} \ln \left(\frac{\rho^{2}}{\rho_{0}^{2}}\right)-\frac{D c^{2}}{f \eta_{0}^{2}}\left(\rho^{2}-\rho_{0}^{2}\right)-\Delta L=0 .
$$

Model intermittent gas lift in the gas-line is also assumed that gas-line is part of a network of the intermittent gas lift system. Intermittent gas lift is consisting of two periods, i.e. closed choke, and opened choke. These phenomena are used as boundary conditions. In the beginning, gas flows from compressor to the gas-line with mass flux constant, a moment later mass flux is raised, and then mass flux constant again. In the outlet, during the closed choke period, gas will not flow to the casing-tubing. However, during opened choke period, injected gas will flow into the casing-tubing with mass flux constant and similar to mass flux in the inlet (Tasmi et al., (2017).

\section{Elevation-Operation Model of Intermittent Gas Lift}

During the gas injection, the choke is opened, and the gas will flow into the tubing-casing annulus. The high pressure of the gas will open the orifice at the bottom of the well so that the gas will enter the tubing. Different fluid phase modes are considered between the annulus and the tubing. Gas will occupy the annulus area, while the tubing will contain gas and liquid from the reservoir. Gas is used to propel the oil to the surface. The velocity of the gas tends to be higher than the velocity of the oil. As a result, the gas does not push the oil completely through the tubing. Therefore, a thin layer of oil, called a film, will be formed around the tubing wall. In this study, the behaviour of gas and oil inside the tubing will be studied thoroughly. Mass and momentum equations are used as the assumption in the analytical model development.

An intermittent gas lift model for the tubing-casing annulus and tubing was developed by Liao (1991). In this paper, Liao's model was used and combined with the gas line model. In the tubing, the intermittent gas lift model is divided into elevation and production operations. The model for the elevation operation is represented by Equations (7) to (27).

$$
\frac{d \vec{Y}_{I I}}{d t}=\vec{F}_{I I}\left(\vec{Y}_{I I}\right), t \in\left(T_{1}, T_{2}\right), \vec{Y}_{I I} \in R^{14}
$$

Initial condition is solution of gas-line model, i.e.

$$
\vec{Y}_{I I}\left(T_{1}\right)=\vec{Y}_{I}\left(T_{1}\right)
$$

where $\vec{Y}_{I I}$ is column matrix (vector) with 14 row 1 column, i.e.

$$
\vec{Y}_{I I}=\left(m_{A}, \rho_{u v}, P_{u v}, P_{g 1}, \rho_{g}, v_{g}, z_{g}, h, v_{s}, v_{f}, z_{s}, P_{g 2}, \rho_{d c}, P_{d c}\right)
$$

and boundary condition

$$
z_{s}\left(T_{2}\right)=z_{w h}
$$

Equation (7) obtained from simplifying the Liao's model is follows

$$
\begin{gathered}
\frac{V_{A}}{2} \frac{d \rho_{d c}}{d t}+\frac{V_{A}}{2} \frac{d \rho_{u v}}{d t}+\frac{d m_{A}}{d t}=0 \\
\frac{d m_{A}}{d t}=-m_{0}+\frac{d m_{v a l v e}}{d t} \\
\frac{d P_{u v}}{d t}-\exp \left(\frac{0.01875 z_{v} \gamma_{g}}{\bar{T}_{A} \bar{Z}_{A}}\right) \frac{d P_{d c}}{d t}=0 \\
\frac{d P_{d c}}{d t}-\frac{Z_{d c} R T_{d c}}{M} \frac{d \rho_{d c}}{d t}=0 \\
\frac{d P_{u v}}{d t}-\frac{Z_{u v} R T_{u v}}{M} \frac{d \rho_{u v}}{d t}=0
\end{gathered}
$$


A Mathematical Model of Intermittent Gas Lift in Elevation-Production Operation with Line-Pack and Line-Drafting (S D Rahmawati, Tasmi, P Sukarno, A Y Gunawan, E Soewono, S Siregar, E L Tobing)

$$
\begin{gathered}
A_{g} z_{g} \frac{d \rho_{g}}{d t}+A_{g} \rho_{g} \frac{d z_{g}}{d t}-2 \pi(r-h) \rho_{g} z_{g} \frac{d h}{d t}-\frac{d m_{\text {valve }}}{d t}=0 \\
\frac{d P_{g 1}}{d t}-\frac{Z R T}{M} \frac{d \rho_{g}}{d t}=0 \\
2 \pi(r-h) z_{g} \frac{d h}{d t}+\left(A_{t}-A_{g}\right) v_{f}-q_{r e s}=0 \\
A_{t} \frac{d z_{s}}{d t}-A_{g} \frac{d z_{g}}{d t}=\left(A_{t}-A_{g}\right) v_{f} \\
\frac{d z_{s}}{d t}=v_{s} \\
\frac{d z_{g}}{d t}=v_{g} \\
\left(z_{s}-z_{g}\right) \frac{d v_{s}}{d t}=-v_{s}^{2}+\left(1-\frac{A_{g}}{A_{t}}\right) v_{f}^{2}+\frac{A_{g}}{A_{t}} v_{g}^{2}+\frac{144 g_{c}\left(P_{g 2}-P_{s}\right)}{\rho_{s}}-g\left(z_{s}-z_{g}\right)-\frac{f_{s} v_{s}^{2}\left(z_{s}-z_{g}\right)}{2 d} \\
\frac{d v_{g}}{d t}=a \frac{d v_{s}}{d t} \\
\frac{d P_{g 2}}{d t}-\frac{d P_{g 1}}{d t}+\left(\frac{f_{g} v_{g}^{2} z_{g}}{288 g_{c} d}+\frac{z_{g} g}{144 g_{c}}\right) \frac{d \rho_{g}}{d t}+\left(\frac{f_{g} \rho_{g} v_{g} z_{g}}{144 g_{c}}\right) \frac{d v_{g}}{d t}+\left(\frac{f_{g} v_{g}^{2} \rho_{g}}{288 g_{c} d}+\frac{\rho_{g} g}{144 g_{c}}\right) \frac{d z_{g}}{d t}=0
\end{gathered}
$$

Equation (11) to (24) can be written as

$$
\boldsymbol{A}\left(\vec{Y}_{I I}\right) \frac{d \vec{Y}_{I I}}{d t}=\vec{c}\left(\vec{Y}_{I I}\right), t \in\left(T_{1}, T_{2}\right), \vec{Y}_{I I} \in R^{14}
$$

Equation (25) can be simplified i.e.

$$
\frac{d \vec{Y}_{I I}}{d t}=\boldsymbol{A}^{-1}\left(\vec{Y}_{I I}\right) \vec{c}\left(\vec{Y}_{I I}\right), t \in\left(T_{1}, T_{2}\right), \vec{Y}_{I I} \in R^{14}
$$

where defined

$$
\boldsymbol{A}^{-\mathbf{1}}\left(\vec{Y}_{I I}\right) \vec{c}\left(\vec{Y}_{I I}\right)=\vec{F}_{I I}\left(\vec{Y}_{I I}\right)
$$

Therefore, model of the production operation is represented by Equation (28) to (34)

$$
\frac{d \vec{Y}_{I I I}}{d t}=\vec{F}_{I I I}\left(\vec{Y}_{I I I}\right), t \in\left(T_{2}, T_{3}\right), \vec{Y}_{I I I} \in R^{14}
$$

with initial condition

$$
\vec{Y}_{I I I}\left(T_{2}\right)=\vec{Y}_{I I}\left(T_{2}\right)
$$

where $\vec{Y}_{I I I}$ is column matrix (vector) with 14 row 1 column, i.e.

$$
\vec{Y}_{I I I}=\left(m_{A}, \rho_{u v}, P_{u v}, P_{g 1}, \rho_{g}, v_{g}, z_{g}, h, v_{s}, v_{f}, z_{s}, P_{g 2}, \rho_{d c}, P_{d c}\right)
$$

and boundary condition

$$
z_{g}\left(T_{3}\right)=z_{w h}
$$

Equation (28) also obtained from simplifying the Liao's model and similar with injection-elevation model with change Equation (22) as follows

$$
\left(z_{w h}-z_{g}\right) \frac{d v_{s}}{d t}=-1.3 v_{s}^{2}+\left(1-\frac{A_{g}}{A_{t}}\right) v_{f}^{2}+\frac{A_{g}}{A_{t}} v_{g}^{2}+\frac{144 g_{c}\left(P_{g 2}-P_{s}\right)}{\rho_{s}}-g\left(z_{w h}-z_{g}\right)-\frac{f_{s} v_{s}^{2}\left(z_{w h}-z_{g}\right)}{2 d}
$$

so that it is obtained

$$
\frac{d \vec{Y}_{I I I}}{d t}=\boldsymbol{A}^{-1}\left(\vec{Y}_{I I I}\right) \vec{c}\left(\vec{Y}_{I I I}\right), \quad t \in\left(T_{2}, T_{3}\right), \vec{Y}_{I I I} \in R^{14}
$$

where defined 


$$
\boldsymbol{A}^{-1}\left(\vec{Y}_{I I}\right) \vec{c}\left(\vec{Y}_{I I I}\right)=\vec{F}_{I I I}\left(\vec{Y}_{I I I}\right)
$$

\section{METHODOLOGY}

Transient models of the intermittent gas lift were solved using numerical approaches. The model consists of phenomena in three domains: the gas line, the tubing-casing annulus, and the tubing. The model was simulated in two steps. First, numerical simulations were carried out on the model of intermittent gas lift in the gas line. This model was solved by the Godunov method (Godunov, 1959). Second, the elevation and the production models were solved using the Runge-Kutta method (Burden \& Faires, 2011). Flowchart to solve this model is presented in Figure 2. The solution of the gas line models was used for the initial value in the elevation model. Therefore, the initial value of the production operation model is the solution to the elevation operation model.

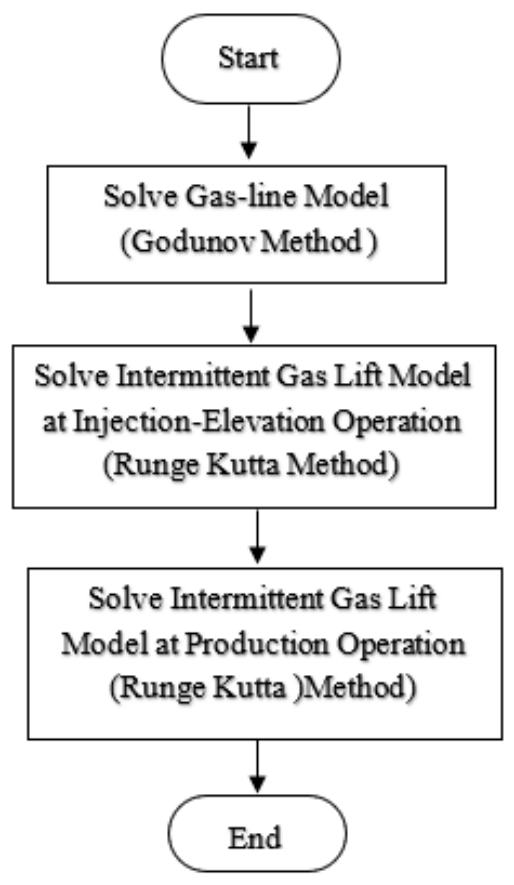

Figure 2. Flowchart for numerical simulation

Simulation data that were used in the gas line include data from a $6000 \mathrm{ft}$ length gas line, with an injection pressure of 600 psia measured in the compressor's discharge, with a gas line diameter of 4 in., gas injection flow rate of $600 \mathrm{Mscfd}$ with 0.675 gas specific gravity. Data for the simulation as follow:

- a casing with 4.892 in. inner diameter.

- a tubing with 2.375 in outer diameter, 1.995 in inner diameter.

- a gas lift valve at $7855 \mathrm{ft}$ depth.

- a discharge valve coefficient of 0.865 .

- a reservoir productivity index of $1 \mathrm{bbl} / \mathrm{day} / \mathrm{psi}$.

- average reservoir pressure of 2000 psia.

\section{RESULT AND DISCUSSION}

After the injected gas enters the tubing, there will be three parts in the tubing, the gas column, the film column, and the slug column. The fluids in each of these sections will continue to flow to the surface during the intermittent gas lift operation. These fluids move with different velocity. Figure 3 presents the dynamics of gas, slug, and film velocities. Shortly after the gas enters the tubing, the fluid velocity (gas, slug, and film) increases. Then once the velocity of fluid flow is stable, the injected gas starts to propel the slug and the fluid velocity in each section will rise gradually. After the top of the slug reaches the wellhead, the slug flows will be continued to the production pipe on the surface. This condition causes the slug velocity to continue to increase. The slug velocity will affect the velocity of the gas and film. The gas velocity and the film velocity also increase. The gas velocity is higher than that of the oil and film. The film velocity is lower than that of the gas and slug, as shown in Figure 3. 


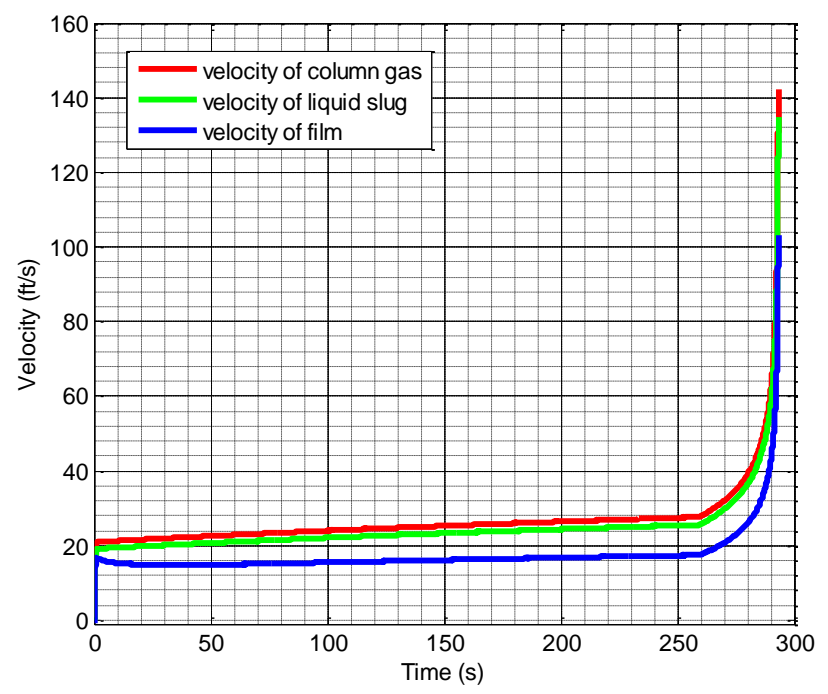

Figure 3. Fluid velocity in the tubing

Figure 3 shows that the film velocity is decreasing. This result is caused by several factors: the film liquid is firmly attached to the wall of the tubing so that a friction factor inhibits the movement or flow of the film with the tubing wall. In addition, the film liquid is also pushed by the injected gas, so that the film is squeezed between the tubing wall and the gas column. The velocity of the slug is shown in Figure 3. During the gas injection, the slug velocity continues to rise. At about $259 \mathrm{~s}$, the slug velocity increases significantly. This happens because the slug has reached the surface. The behaviour of the gas velocity is similar to the slug velocity and is shown in Figure 3.

Figure 4 presents the dynamics of the gas and slug position in the tubing. During the elevation process, the gas position is always under the slug. This dynamic shows that the gas successfully propels the slug to the surface. Figure 4 shows that the distance between the slug and gas levels decreases as the fluid moves closer to the surface. This means that the volume of slug production to the surface decreases. The film that forms in the tubing wall also contributes to this decrease, and the film will not move to the surface.

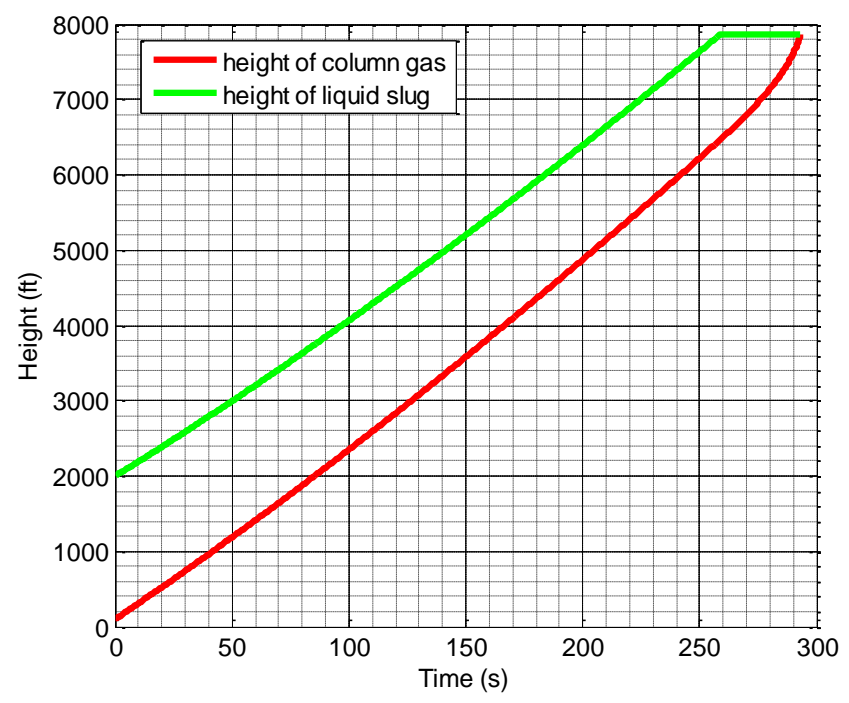

Figure 4. Height of slug and gas in the tubing

After the top of the slug position is equal to the height of the wellhead, the intermittent process changes from the elevation operation to the production operation. In the production operation, the height of the slug is always equal to the wellhead position, and the gas continues to push the slug. When the top of the gas injection column is equal to the wellhead, the production operation ends. The slug will continue to flow into the production network. Therefore, the total volume of slug production from the reservoir can be determined. 
Figure 5 shows that the film thickness is monotonically decreasing as a function of time. This means that the film has thinned. In this model, the height of the liquid film is assumed to equal to the height of the gas column, so that the position of the liquid film rises following the movement of the gas in the tubing. The position of the liquid film affects the film thickness; that is, the higher the position of the film, the thinner the layer of film on the tubing.

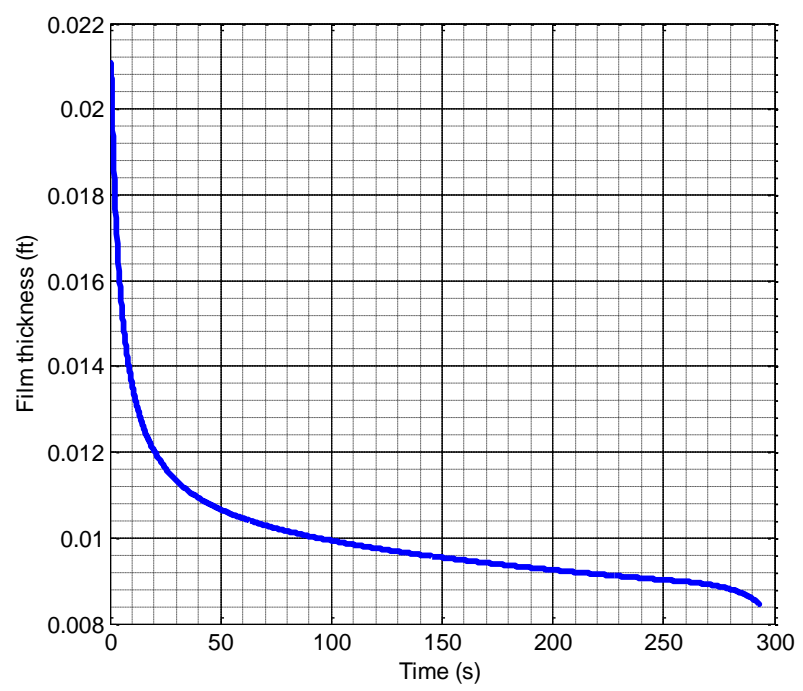

Figure 5. Film thickness

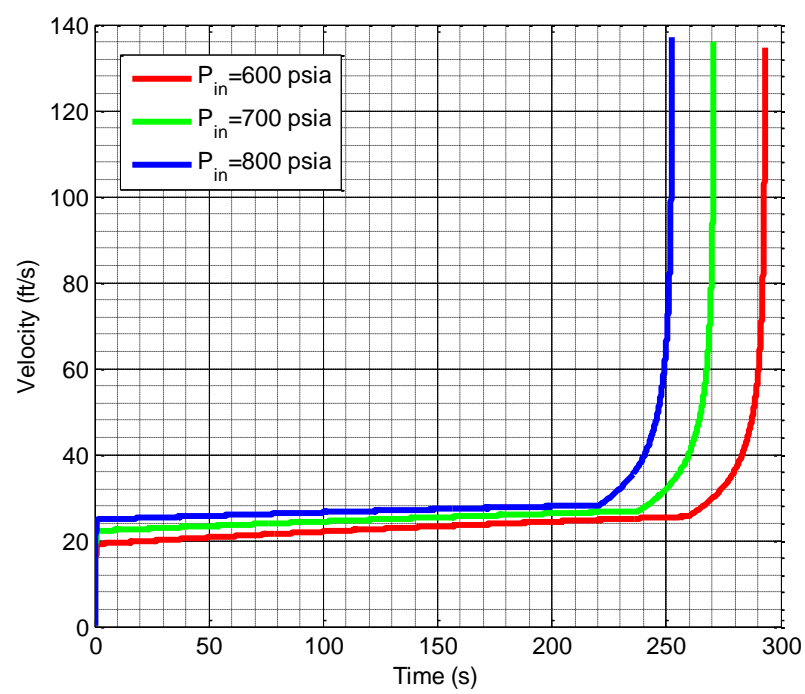

Figure 6. Effect of pressure injection sensitivity to the fluid velocity in the tubing

Furthermore, the sensitivity of the gas injection rate and the gas injection pressure was evaluated to determine the effect of these parameters on the intermittent gas lift dynamic observations (Figures 6 to 9). The sensitivity of the fluid velocity and the film thickness to the gas injection pressure are shown in Figure 6 and Figure 7, respectively. Figure 6 shows that increasing the injection pressure increases the fluid velocity in the tubing. However, Figure 7 shows that the film thickness decreases with increasing injection pressure. 
A Mathematical Model of Intermittent Gas Lift in Elevation-Production Operation with Line-Pack and Line-Drafting

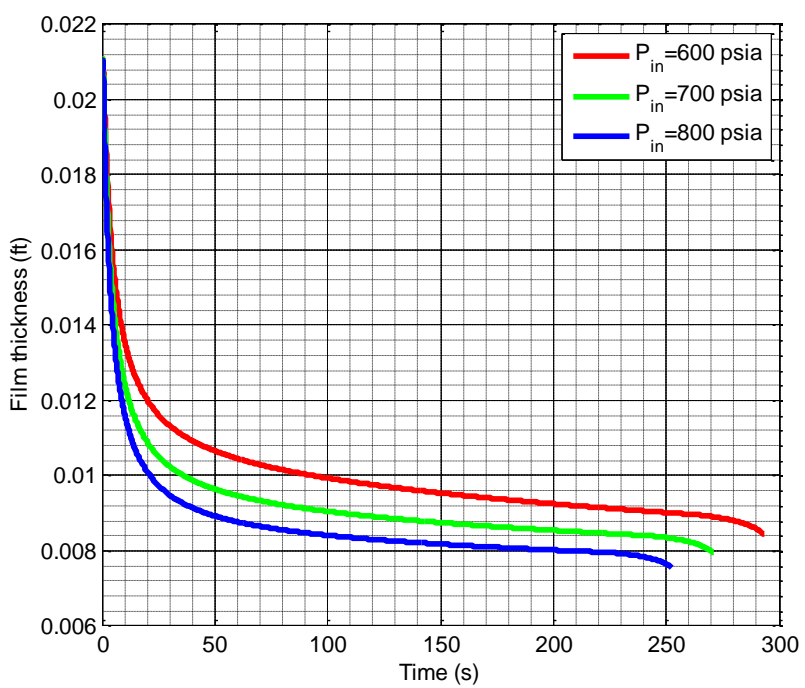

Figure 7. Effect of pressure injection sensitivity to the film thickness

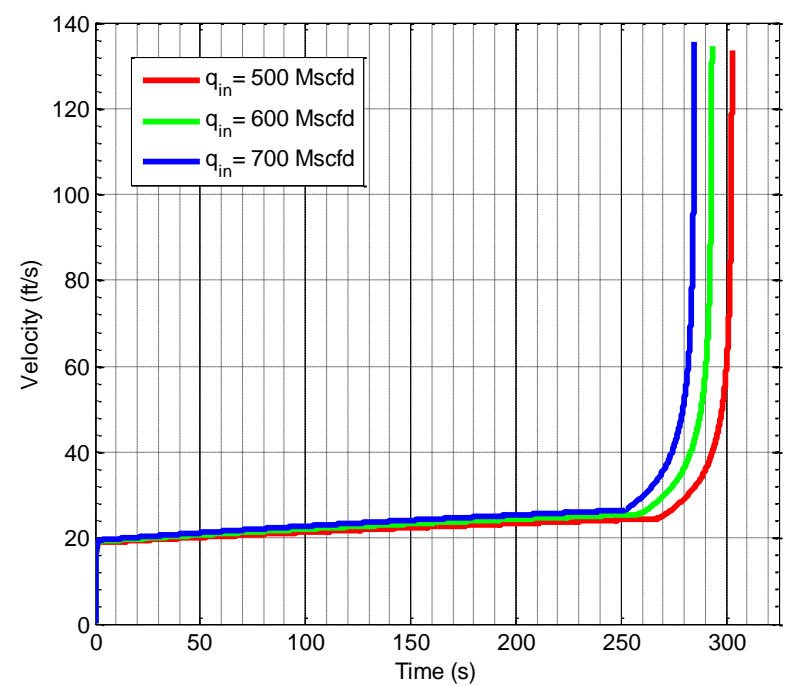

Figure 8. Effect of gas rate injection sensitivity to the fluid velocity in the tubing

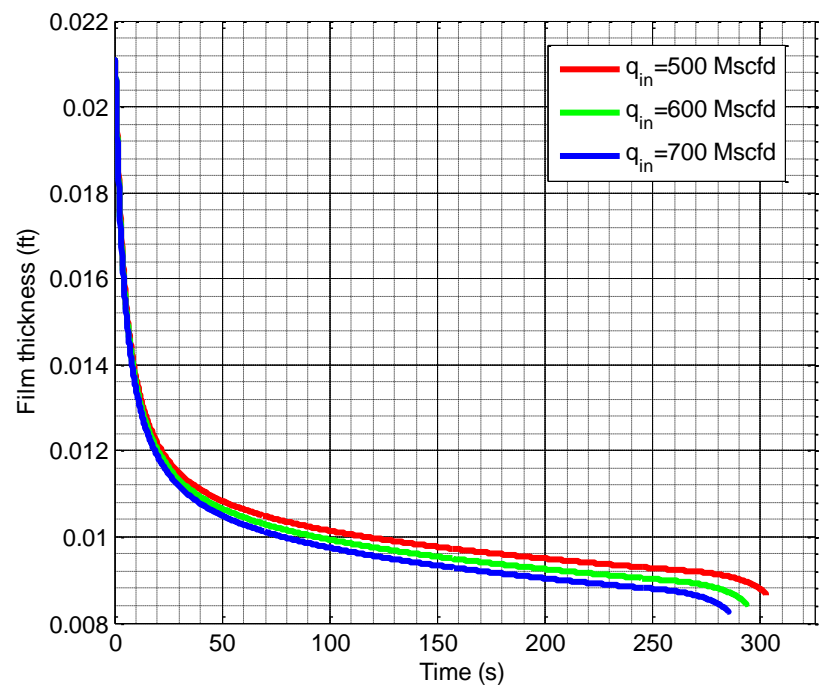

Figure 9. Effect of gas rate injection sensitivity to the film thickness 
Figure 8 presents the effect of the gas injection rate on the fluid velocity in the tubing. Figure 8 shows that increasing the gas injection rate increases the fluid velocity in the tubing. As mentioned earlier, the fluid velocity rises significantly at about $260 \mathrm{~s}$ when the oil reaches the surface. Figure 9 shows the effect of the gas injection rate on the film thickness in the tubing wall. The film thickness decreases when the gas injection rate increases. However, with the changes in the gas injection rate studied in this case, the decrease of the film thickness was not significant. Table 1 shows the average value of slug velocity and film thickness when the pressure of the gas injected is varied. The results show, the higher the value of gas injection pressure, then the faster the slug velocity and the thinner the film thickness that will be left around the wall. Table 2 depicts the average value of slug velocity and film thickness when the gas injection rate is varied. The higher the gas injection rate, hence the faster the slug velocity and the thinner of the film thickness. The results shown in Table 1 and Table 2 shows the same pattern and reliable with the real condition.

Table 1. Average value of slug velocity and film thickness as an effect of pressure gas injection value

\begin{tabular}{llll}
\hline Variable & \multicolumn{3}{c}{$P_{\text {inj }}$ (psia) } \\
& 600 & 700 & 800 \\
\hline Mean of Velocity (ft/s) & 32.54 & 34.71 & 37.03 \\
Mean of Film thickness (ft) & 0.009822 & 0.009148 & 0.00863 \\
\hline
\end{tabular}

Table 2. Average value of velocity and film thickness as an effect of gas rate injection

\begin{tabular}{llll}
\hline Variable & \multicolumn{3}{l}{$q_{\text {inj }}$ (Mscfd) } \\
& 500 & 600 & 700 \\
\hline Mean of Velocity (ft/s) & 31.3 & 32.54 & 33.62 \\
Mean of Film thickness (ft) & 0.01002 & 0.009822 & 0.009647 \\
\hline
\end{tabular}

\section{CONCLUSION}

- A transient model of an intermittent gas lift was constructed based on physical phenomena. The model is divided into three domains, that is modelling the gas injection flowline, the tubing-casing annulus, and the tubing.

- The model in the gas injection flowline describes the line-pack and line-drafting phenomena. Furthermore, the model in the tubing-casing annulus and tubing describes the fluid flow when the choke is opened. The models were simulated by the Godunov and Runge-Kutta methods. The Godunov method was implemented to solve partial differential problem formulation in the gas line model, and the Runge-Kutta method was applied to the tubing-casing annulus and tubing.

- The model successfully described the behaviour of the variables most affected during the intermittent gas lift process. It was observed that the height of gas was lower than the height of the oil, which means that the injected gas successfully pushed the oil to the surface.

- Furthermore, the film thickness formed along the tubing shows the liquid that cannot be produced and will fall back to the bottom of the well.

- The volume of oil production at the surface can be calculated based on the volume of the film. Moreover, these variables are also affected by the gas rate and pressure injection in the compressor.

- The higher the pressure and the rate of gas injection will give velocity increment of the fluid in the tubing. These cause reduction in the film thickness in the tubing. Therefore, the model can be used to design a system for the intermittent gas lift production process. 
A Mathematical Model of Intermittent Gas Lift in Elevation-Production Operation with Line-Pack and Line-Drafting

Phenomena in a Gas Line

(S D Rahmawati, Tasmi, P Sukarno, A Y Gunawan, E Soewono, S Siregar, E L Tobing)

\section{Acknowledgements}

This research was funded by Directorate General of Higher Education under Decentralization Scheme (Hibah Desentralisasi Dikti) 2017.

\section{References}

Adewumi, M. A., \& Zhou, J. (1995, October). The Development And Testing of a New Flow Equation. PSIG Annual Meeting.

Aliev, F. A., \& Jamalbayov, M. A. (2015, October). Theoretical Basics of Mathematical Modeling of the Gas Lift Process in the Well-Reservoir System. SPE Russian Petroleum Technology Conference. https://doi.org/10.2118/176641-ms

Bordalo, S. N., \& Filho, C. O. C. (2007). MODELING AND PERFORMANCE ASSESSMENT OF INVERTED INTERMITTENT GAS LIFT. Revista de Engenharia Térmica, 6(1), 103. https://doi.org/10.5380/reterm.v6i1.61823

Brill, J. P. (1967). An Analytical Description of Liquid Slug Flow In Small-Diameter Vertical Conduits. Journal of Petroleum Technology, 19(03), 419-432. https://doi.org/10.2118/1526-pa

Brown, K. E. (1980). The Technology of Artificial Lift Methods Vol. 2a, Introduction of artificial lift systems, beam pumping: design and analysis, gas lift. Petroleum Publishing Company.

Burden, R. L., \& Faires, J. D. (2011). Numerical Analysis (M. Julet (ed.); 9th ed.). Richard Stratton.

Filho, C. de O. C., \& Bordalo, S. N. (2003). A Simultaneous and Coupled Simulation Scheme for the Conventional Intermittent Gas Lift. Congresso Brasileiro de Engenharia Mecânica, COBEM.

Fitrianti, F., Putra, D. F., \& Cendra, D. (2018). The Critical Investigation on Essential Parameters to Optimize the Gas Lift Performance In "J" Field Using Prosper Modelling. Journal of Earth Energy Engineering, 7(2), 46-54. https://doi.org/10.25299/jeee.2018.vol7(2).2269

Godunov, S. K. (1959). A difference method for numerical calculation of discontinuous solutions of the equations of hydrodynamics. Matematicheskii Sbornik, 47(89)(3), 271-306.

Liao, T. (1991). Mechanistic Modeling of Intermittent Gas Lift. University of Tulsa.

Musnal, A., \& Fitrianti, F. (2017). Optimasi Gas Injeksi Pada Sembur Buatan Gas Lift Untuk Meningkatkan Besarnya Laju Produksi Minyak Maksimum Dan Evaluasi penghentian Kegiatan Gas Lift, Pada Lapangan Libo PT. Chevron Pacific Indonesia Duri. Journal of Earth Energy Engineering, 6(2), 36-47. https://doi.org/10.22549/jeee.v6i2.993

Neely, A. B., Montgomery, J. W., \& Vogel, J. V. (1974). A Field Test and Analytical Study of Intermittent Gas Lift. Society of Petroleum Engineers Journal, 14(05), 502-512. https://doi.org/10.2118/4538PA

Pestana, T. (2011). Gas Lift Intermitente: Uma Modelagem e Implementação Computacional. Universidade Federal da Bahia.

Pestana, T., Bordalo, S., \& De Almeida Barreto Filho, M. (2013). Numerical simulation in the time domain of the intermittent gas-lift and its variants for petroleum wells. SPE Artificial Lift Conference Americas: Artificial Lift: Where Do We Go From Here, 28-34. https://doi.org/10.2118/165007-ms

Santos, O. G., Bordalo, S. N., \& Alhanati, F. J. S. (2001). Study of the dynamics, optimization and selection of intermittent gas-lift methods-a comprehensive model. Journal of Petroleum Science and Engineering, 32(2-4), 231-248. https://doi.org/10.1016/S0920-4105(01)00164-4

Shao, W., Boiko, I., \& Al-Durra, A. (2016). Plastic bag model of the artificial gas lift system for slug flow analysis. Journal of Natural Gas Science and Engineering, 33, 573-586. https://doi.org/10.1016/j.jngse.2016.05.055

Sulistyarso, H. B., Trihandaru, S., Mucharam, L., Siregar, S., Saputra, I., \& Canggih, S. (2004). Solusi Model Aliran Gas Dalam Pipa pada Kondisi Line Packing Menggunakan Skema Richtmyer. ITB Journal of Sciences, 36(2), 159-177. https://doi.org/10.5614/itbj.sci.2004.36.2.5

Tasmi, T., Rahmawati, S. D., Sukarno, P., \& Soewono, E. (2017). Applications of line-pack model of gas flow in intermittent gas lift injection line. Journal of Petroleum Science and Engineering, 157, 930940. https://doi.org/10.1016/j.petrol.2017.08.010 
Zhou, J., \& Adewumi, M. A. (1996). Simulation of transients in natural gas pipelines. SPE Production \& Facilities, 11(4), 208. https://doi.org/10.2118/31024-pa

\section{Nomenclature}

$$
\begin{aligned}
& \boldsymbol{A} \text { : Matrix obtained from simplification Equation (11) to (24) } \\
& A_{t} \quad \text { : Area of tubing, } f t^{2} \\
& A_{g} \quad: \quad \text { Area of Gas Column, } f t^{2} \\
& \text { a : Gas velocity coefficient } \\
& \text { c : Acoustic velocity of gas, } \mathrm{ft} / \mathrm{s} \\
& \vec{c} \quad \text { Vector obtained from simplification Equation (11) to (24) } \\
& D \quad \text { : Diameter of gas-line, } f t \\
& d \quad \text { : Diameter of tubing, } f t \\
& \vec{F}_{I} \quad \text { : Vector in Equation (4) } \\
& \vec{F}_{I I} \quad \text { Vector of multiplication result in Equation (27) } \\
& \vec{F}_{I I I} \quad \text { Vector of multiplication result in Equation (34) } \\
& f \quad: \quad \text { Friction of gas in gas-line } \\
& f_{g} \quad: \text { Friction of gas in tubing } \\
& f_{s} \quad: \quad \text { Friction of slug } \\
& \vec{G}_{I} \quad: \text { Vector in Equation (3) } \\
& g_{c} \quad \text { : Gravitational acceleration, } l b_{m}-f t / l b_{f}-s^{2} \\
& g \text { : Gravity, } f t / s^{2} \\
& h \quad: \text { Film thickness, } f t \\
& L \quad \text { : Length of gas-line, } f t \\
& \text { M : Molecular weight of gas } \mathrm{lbm} / \mathrm{lbm}-\text { mole } \\
& m_{A} \quad: \text { Gas mass in the annulus, } l b m \\
& m_{\text {valve }} \text { : Gas mass in the valve, } l b m \\
& P_{u v} \quad: \text { Gas pressure in the upstream valve, } p \text { sia } \\
& P_{d c} \quad: \text { Gas pressure in the downstream choke, psia } \\
& P_{g 1} \quad \text { : Pressure of gas in the bottom of column gas, } p s i a \\
& P_{g 2} \quad \text { : Pressure of gas in the top of column gas, psia } \\
& R \quad \text { : Gas constant } \\
& r \quad: \quad \text { Radius of tubing, } f t \\
& T \quad \text { : Temperature, }{ }^{0} R \\
& \bar{T}_{A} \quad \text { : The average of temperature in the annulus, }{ }^{0} R \\
& T_{d c} \quad \text { : Temperature of downstream choke, }{ }^{0} R \\
& T_{u v} \quad \text { : Temperature in the upstream valve, }{ }^{0} R \\
& T_{1} \quad \text { : Period of closed choke, } s \\
& T_{2} \quad \text { : Period of injection-elevation operation, } s \\
& T_{3} \quad \text { : Time of production operation, } s
\end{aligned}
$$


A Mathematical Model of Intermittent Gas Lift in Elevation-Production Operation with Line-Pack and Line-Drafting

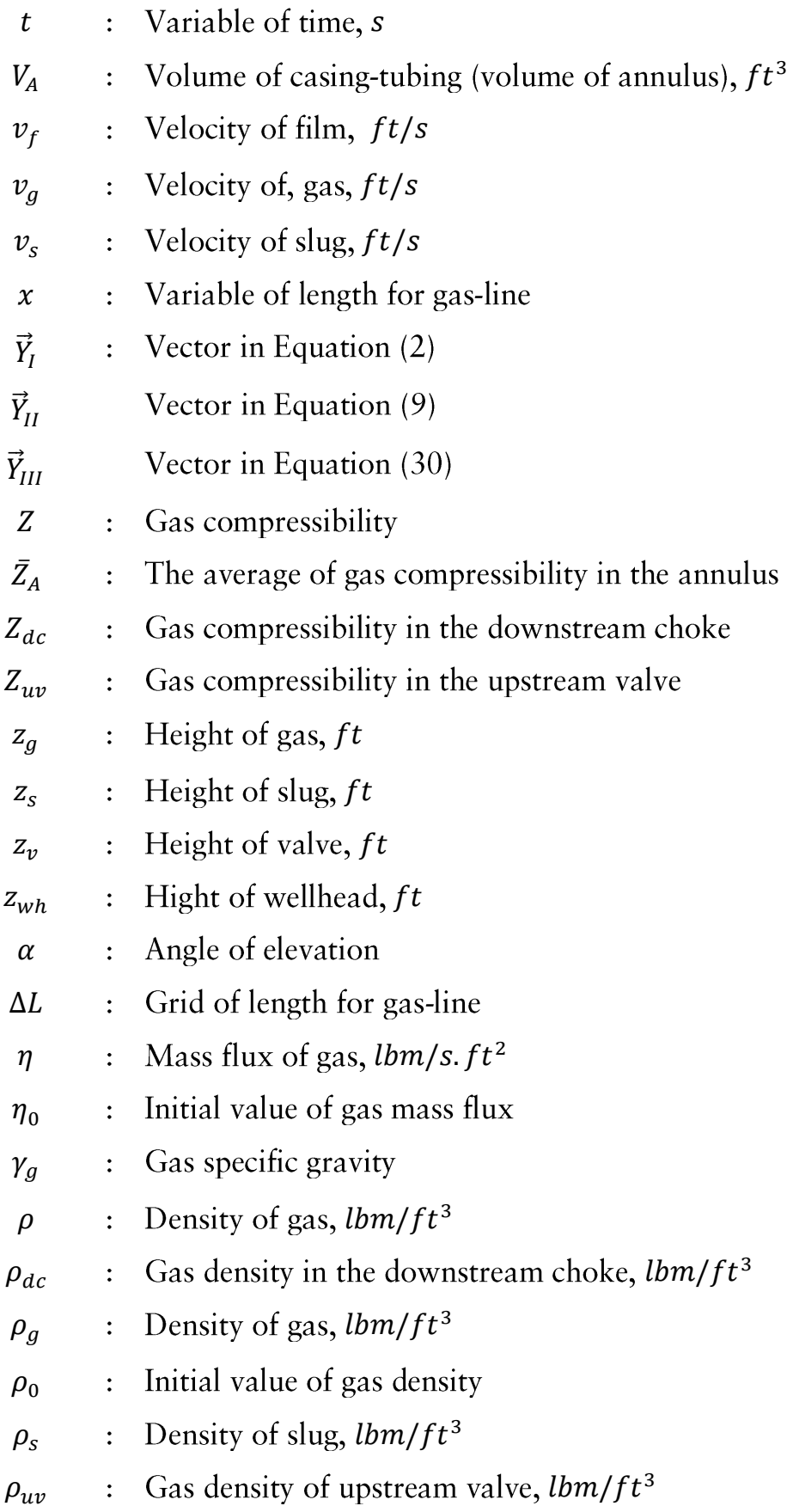

\section{Appendix}

Pseudocode for numerical simulation

1. Pseudocode to solve gas-line model

Function [pressure_outlet, flowrate_outlet] = gas_line ( $t$, P_inj, q_inj)

Input parameter

Input initial condition

Loop for $\mathrm{i}<=\mathrm{t}$

Input boundary in inlet

Loop for $j=2$ until length of gas line

$$
\rho(j)=\ldots . . \% \text { Godunov Scheme }
$$




$$
\eta(j)=\ldots . . \% \text { Godunov Scheme }
$$

End

Input boundary in outlet

Update value of $\rho(j)$ and $\eta(j)$

Calculate of pressure and flowrate in outlet

End

End

2. Pseudocode to solve intermittent gas lift model for injection-elevation and production model Function $\mathrm{dxdt}=$ modeltubing $(\mathrm{t}, \mathrm{x})$

Input parameter

If $x(7)<z_{-} w h$

Parameter for injection-elevation operation

Else

Parameter for production operation

end

$\mathrm{dxdt}=$ zeros $(14,1) \%$ ordinary differential of equation (intermittent gas lift)

$\operatorname{dxdt}(1)=\ldots$

$\operatorname{dxdt}(2)=\ldots$

$\operatorname{dxdt}(14)=\ldots$

end

3. Pseudocode for main program

Input parameter

[pressure_outlet, flowrate_outlet]= gas_line(t, P_inj, q_inj)

$P_{d c}=$ pressure_outlet

Input initial value

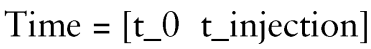

$[\mathrm{T}, \mathrm{X}]=$ ode $45(\ldots)$ \% runge kutta method

Plot solution T vs X 